\title{
Endoscopic ultrasound-guided sclerosant injection and coil embolization of bleeding gastric varices
}

The usefulness of endoscopic ultrasound (EUS) as a diagnostic tool is well known; however, its therapeutic implications are upcoming. There are data for the use of cyanoacrylate glue (CYA) as a temporary measure to control bleeding in gastric varices, followed either by a transjugular intrahepatic portosystemic shunt (TIPS) procedure or by balloon-occluded retrograde transvenous obliteration (BRTO). A 44-year-old Asian man with hepatitis B virus cirrhosis complicated by hepatocellular cancer causing portal vein thrombosis presented with melena and bright red blood per rectum with associated dizziness, hemodynamic instability, and an initial hemoglobin of $6.5 \mathrm{~g} / \mathrm{dL}$. He had a history of bleeding esophageal varices that had been banded in the past, with prior EGD showing non bleeding gastric varices. An emergent repeat esophagogastroduodenoscopy showed no residual esophageal varices and the stomach was filled with blood clots and fresh blood that were preventing identification of the bleeding source, but he had known prior gastric varices making that to be the most likely source of bleeding. An emergent EUS showed multiple gastric varices with active blood flow ( $\mathbf{F i g} \mathbf{1}$ ). CYA was unavailable and, in view of the patient's hemodynamic instability, a decision was made to emergently inject $3 \%$ sodium tetradecyl sulfate (STS), a sclerosing agent, under EUS guidance. Doppler ultrasound confirmed a significant decrease in the blood flow to the gastric varices.

Following this an interventional radiology opinion was sought, but the patient was deemed a poor candidate for TIPS and BRTO because of his portal vein thrombosis and advanced cirrhosis. The following day, on repeat EUS, two deep gastric varices were therefore identified and injected with two tornado $4-\mathrm{mm} \times$ $30-\mathrm{mm}$ coils, followed by a further $3 \mathrm{~mL}$

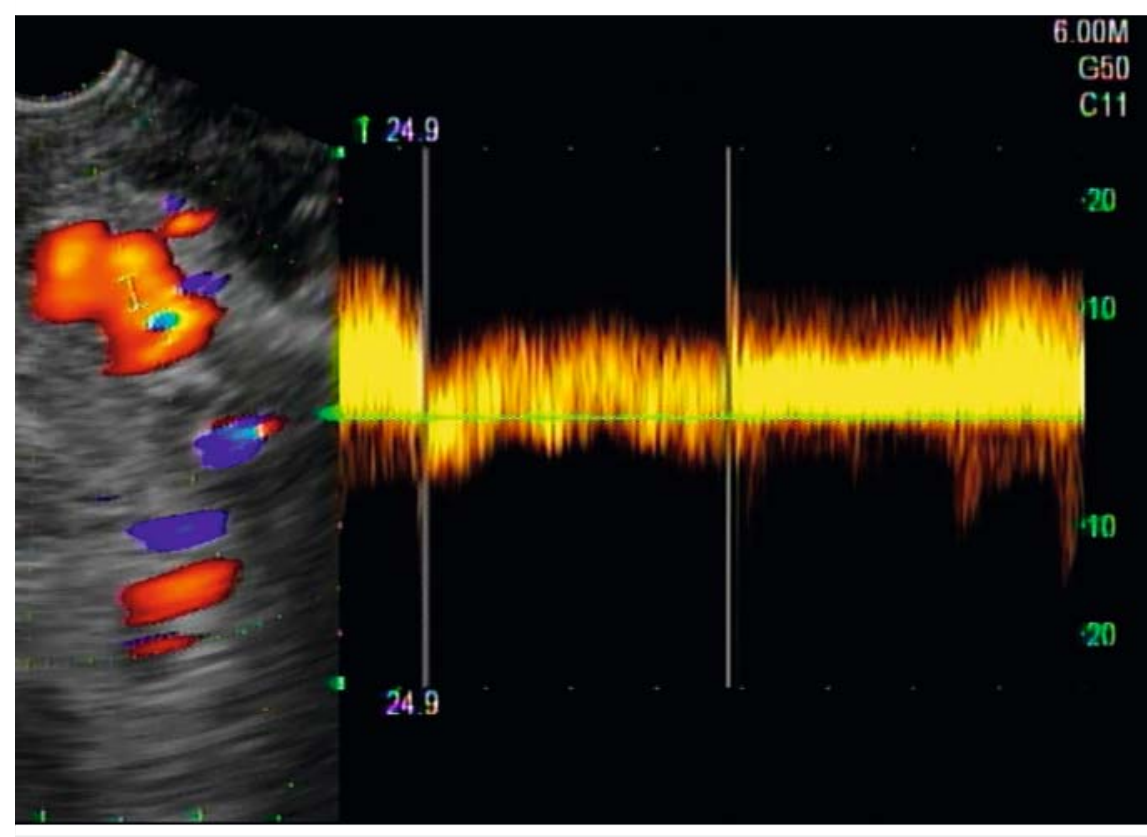

Fig. 1 Endoscopic ultrasound Doppler showing the large gastric varices and blood flow to these varices.

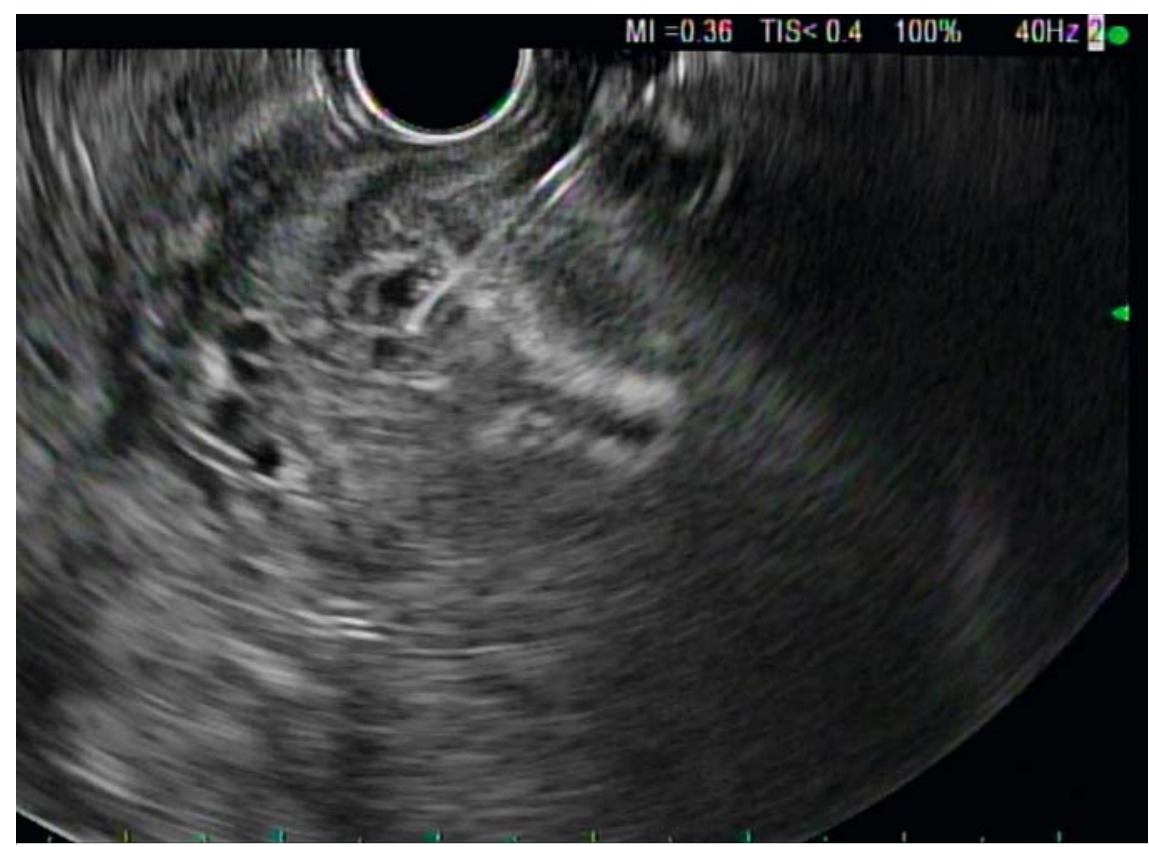

Fig. 2 Image during endoscopic ultrasound-guided injection of the sclerosing agent and coil embolization of the gastric varices. 


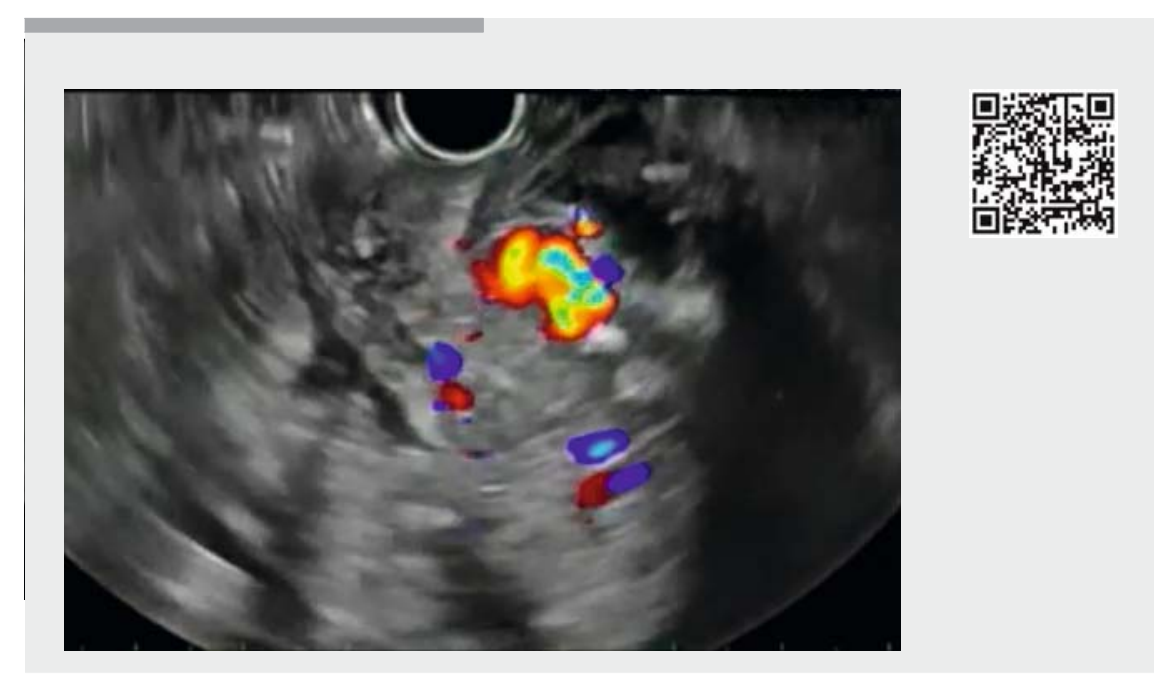

$\nabla$ Video 1 Endoscopic ultrasound-guided sclerosant injection and coil embolization of bleeding gastric varices.

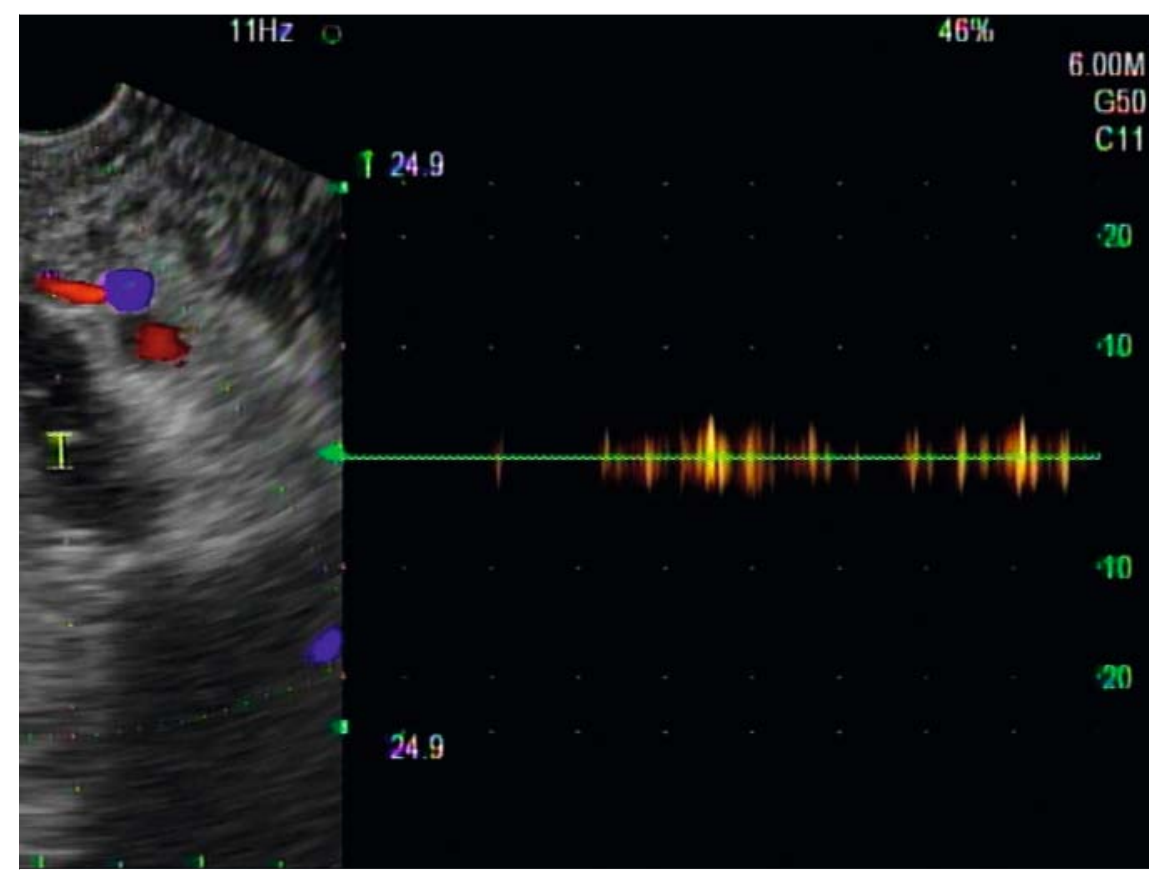

- Fig. 3 Repeat endoscopic ultrasound Doppler showing minimal to absent blood flow to the varices following sclerosing agent injection and coil embolization. of $3 \%$ STS ( $>$ Fig. 2 ; $>$ Video 1 ). Successful hemostasis was confirmed with absent blood flow on follow-up Doppler ( Fig.3). A week later, the patient's hemoglobin had improved to $9.6 \mathrm{~g} / \mathrm{dL}$ with no further bleeding episodes.

The prevalence of gastric varices is around $15 \%$ in patients with cirrhosis [1]. Up to $30 \%$ of all gastric variceal bleeds are severe, with higher rates of rebleeding and mortality. When CYA or a sclerosing agent are used on their own, they have high rates of systemic embolization and rebleeding, therefore coil embolization helps prolong hemostasis and minimize complications [2]. The data show that sclerosing agents can cause more ulcer formation at the injection site and rebleeding than CYA. However, CYA is not available at all centers and, for patients who are poor candidates for TIPS/ BRTO, alternative therapies must be employed in emergent situations. EUS-guided coil embolization is a novel approach to achieve prolonged hemostasis. To our knowledge, this is the first case demonstrating the utility of sclerosing agents followed by coil embolization in a patient with bleeding gastric varices.

Endoscopy_UCTN_Code_TTT_1AO_2AN

Competing interests

None

The authors

Bhavtosh Dedania', Keshav Kukreja² ${ }^{2}$, Tomas Davee $^{1,3}$, Manoop S. Bhutani ${ }^{3}$

1 Division of Gastroenterology, Hepatology \& Nutrition, University of Texas Health Science Center at Houston, Houston, Texas, USA

2 Department of Internal Medicine, University of Texas Health Science Center at Houston, Houston, Texas, USA

3 Division of Gastroenterology, Hepatology \& Nutrition, University of Texas MD Anderson Cancer Center, Houston, Texas, USA 


\section{Manoop S. Bhutani, MD}

Gastroenterology, Hepatology and Nutrition Department, UT MD Anderson Cancer Center, Unit 1466, 1515 Holcombe Blvd., Houston, Texas 77030, USA

Fax: +1-713-563-4398

Manoop.Bhutani@mdanderson.org

\section{References}

[1] Frischtak $\mathrm{H}$ et al. Therapeutic options for bleeding oesophageal varices: cyanoacrylate and balloon-occluded retrograde obliteration (BRTO). BMJ Case Rep. doi:10.1136/bcr-2017-219615

[2] Bhat YM, Weilert F, Fredrick RT et al. EUSguided treatment of gastric fundal varices with combined injection of coils and cyanoacrylate glue: a large U.S. experience over 6 years (with video). Gastrointest Endosc 2016; 83: $1164-1172$

\section{Bibliography}

DOI https://doi.org/10.1055/s-0043-122140

Published online: 12.1.2018

Endoscopy 2018; 50: 283-285

(C) Georg Thieme Verlag KG

Stuttgart · New York

ISSN 0013-726X

\section{ENDOSCOPY E-VIDEOS}

https://eref.thieme.de/e-videos

口回 Endoscopy E-Videos is a free access online section, reporting 回舴: on interesting cases and new techniques in gastroenterological endoscopy. All papers include a high quality video and all contributions are freely accessible online.

This section has its own submission website at

https://mc.manuscriptcentral.com/e-videos 